\title{
Lacrimal Sac
}

National Cancer Institute

\section{Source}

National Cancer Institute. Lacrimal Sac. NCI Thesaurus. Code C32909.

An oval shaped cavity at the upper extremity of the nasal duct. 